\title{
Timing of the First Antenatal Care Visit and Associated Risk Factors in Rural Parts of Ethiopia
}

\author{
Lema Abate Adulo, Mizan-Tepi University, Ethiopia \\ Sali Suleman Hassen, Mizan-Tepi University, Ethiopia \\ Asrat Chernet, Wolaita Sodo University, Ethiopia
}

\begin{abstract}
Early antenatal care visits promote early detection and treatment of complications during pregnancy. The aim of this study was to assess the timing of the first antenatal care visit and associated factors in rural parts of Ethiopia. Only 3,065 women from 2016 Ethiopian Demographic and Health Survey in rural area were included in this study. The descriptive and binary logistic regression analysis were used to identify the determinants associated with the timing of the first antenatal care visit. This study revealed that $31 \%$ of women visited the first antenatal care within the first three months. The study revealed that women's education, maternal age, region, media access, occupation, distance from health facility, wealth index, pregnancy complication, and plan for pregnancy had significant effects on the timing of the first antenatal care visit. To initiate pregnant mothers to attend the first ANC visit in a timely manner, community-based services like media coverage, education, transportation, and awareness about the necessity of having antenatal care service early is mandatory.
\end{abstract}

\section{KEYWORDS}

Antenatal Care, Early Visit, Risk Factors

\section{BACKGROUND}

Pregnancy-related deaths and diseases remain unacceptably high worldwide, around 303,000 women and adolescent girls and 2.7 million babies during the first 28 days of life, died due to pregnancy and childbirth related complications and 2.6 million babies were stillborn in 2015 (Alkema L, 2016). An increased access to and use of higher-quality health care during pregnancy and childbirth can prevent many deaths and diseases, as well as improve women and adolescent girls' experience of pregnancy and childbirth (WHO, 2020). According to WHO reports in 2017, 295, 000 women worldwide lost their lives during and following pregnancy and childbirth, about $86 \%$ of those deaths occurred in sub-Saharan Africa and South Asia (World health statistics, 2020).

Nearly $99 \%$ maternal mortality and $98 \%$ child mortality occurred in low and middle-income countries. If the pregnant women or adolescent girls had been able to visit antenatal care (ANC) properly, the maternal death could be preventable (WHO, 2016). In 2016, WHO developed new model for the antenatal care visits, which recommends pregnant women to have their first contact during the first 12 weeks' gestation, and then follow the time schedule as 20, 26, 30, 34,36, 38 and 
40 weeks' gestation. ANC visit brings positive pregnancy outcomes when the booking starts within the recommended pregnancy period and if the frequencies of contacts are adequate (WHO, 2016). Giving attention for maternal and fetal assessments to detect complications, improving support and communication between healthcare providers and pregnant women, increases the likelihood of positive pregnancy outcomes (Tuncalp Ö 2017).

Several studies indicated that women, not empowered in household decision-making or exposed to any form of mass media, have lower ANC utilization (Assefa E, 2017), (Acharya D, 2015), (Collins $\mathrm{Z}, 2015)$. Women from rural communities have had fewer ANC visits with significant variations in the number of ANC visits compared to urban, Muslim women had fewer ANC visits than Christian women across all survey years (Ousman SK, 2019).

Mothers who visited antenatal care timely in their pregnancy period had enough time for essential and feasible interventions, prevention of complications and early identification of underlying conditions (FMOH, 2014). Study conducted in Debre Markos indicated that women from rural areas are more likely to delay on first ANC visit (Ewunetie et al., 2018). According to Ethiopian Demographic Health Survey report of 2016, about $37 \%$ of women were not visited ANC service during their pregnancy time. Most of women (41\%) from rural were more likely to have had no ANC visits compared to women from urban (10\%) and only $20 \%$ of women had their first ANC during the first trimester of pregnancy (CSA, 2016). As shown in the reports of Ethiopian Demographic health survey a few women were experienced the timely ANC visit and most women from rural area not visited timely. Therefore, this study intended to investigate the timing of the first antenatal care utilization and associated risk factors in rural parts of Ethiopia.

\section{METHODS}

\section{Study Design And Data Set}

In Ethiopia, there are nine regions and two administrative cities total. This study conducted in rural parts of nine regions and one city administration by excluding mothers from urban. The representative sample of all rural dweller women aged 15-49 were taken. The data used for this study were taken from the Ethiopian Demographic and Health Survey implemented by the Central Statistical Agency (CSA) at the request of the Federal Ministry of Health (FMOH) in 2016 and it is the fourth inclusive survey. The survey was a population-based cross-sectional study obtained between January 18, 2016 and June 27, 2016, through the country and data are available at https://www.dhsprogram.com/ data/dataset_admin/login_main.cfm DHS database. From samples of 18,008 households selected for interview, 16,650 households interviewed for individual interview and 16,583 eligible women identified from the interviewed household. However, total 15,683 women aged 15-49 were participated and completed full information during interview (CSA, 2016). About 3,065 women aged 15-49 who were from rural residence considered to identify timely contact status of mothers with healthcare service providers in this study.

\section{Study Variables}

The dependent variable in this study was the timing of ANC visit status. Timing of ANC visit defined as booking of ANC visit according to WHO recommendation time schedule. Mothers who visited the health facility during pregnancy less than or equal to 12 weeks of gestation considered as early visited and greater than 12 weeks considered as late (WHO, 2016). The explanatory variables considered in this study selected based on different articles published previously (Ayele D. G., 2016) (Gebresilassie et al., 2019) (Solomon G. et al., 2016). Socio-demographic variables (maternal age, region, husbands educational level, mother's educational level, mother occupation, husband occupation, marital status, wealth index and Media exposure), Fertility related variables (Pregnancy complication and Pregnancy 
termination) and ANC visit related variables (Distance from healthcare facility, planned pregnancy and peer influence).

\section{Statistical Data Analysis}

The data extracted from EDHS 2016 for this study were cleaned, coded and analyzed using the SPSS version 20 and R- version 3.6.2 statistical software. For statistical analysis, the descriptive analysis using frequency and percentage, and from inferential statistics multiple binary logistic regression applied to identify the risk factors of timely booking at pregnancy time of women. The predictor variables those are significant in the univariable analysis at $25 \%$ (p-value $<0.25$ ) level of significance were included in the multivariable binary logistic regression analysis. The estimated odds ratios and $95 \%$ confidence intervals with p-value less than $5 \%$ indicates that the variables are statistically significant in multivariable analysis and used to interpret results.

\section{RESULTS}

\section{Socio-Demographic Characteristics Of Respondents}

Among 3065 participants in the study, nine hundred Forty six (31\%) of women visited first ANC within twelve weeks, while majority of participants $69 \%$ visited after twelve weeks in this study. About $1880(61.34 \%$ ) women were not attended formal education, and from those women five hundred forty (28.7\%) booked first ANC visit early. Majority of participants 1606(52.4\%) belongs to poorer wealth index, and of which 457(28.5\%) women attended their first ANC checkup timely. Out of 827(26.98\%) of the respondents from the richer wealth index, about 281(34\%) followed their ANC service timely. Above one fourth of women (27.93\%) were in the age group 25 and 29 years, and among those only $273(31.9 \%)$ followed the first ANC checkup within the recommended time interval. Only seventy (2.28\%) participants included from age group 44 and 49 years (Table 1$)$.

Among the participants in the study, 128(4.18\%) women were from the Dire Dawa city administration and from those women $73(57.4 \%)$ were attended ANC visit within the first three months. Five hundred forty $(17.62 \%)$ were from South Nation Nationality People Region, and of which $110(20.4 \%)$ booked their first ANC visit early. Approximately half of participants were single and from which only 444(28.9\%) attended their first ANC contact early. Only seventy-seven (31.4\%) women was belonged to husbands who had no any work and they were visited their first ANC early. About 667(21.76\%) women husbands were private workers. Among women in the study, four hundred ninety-five (29.3\%) women had no any work and visited ANC earlier, whereas two hundred fifteen (31.8\%) were housewife's and visited ANC earlier. Only four hundred sixteen (29.6\%) women who belongs to husbands of no education were attended their first visit within recommended time (Table 1).

\section{Fertility Related Characteristics Of Respondents}

Out of a total participant, 1266(41.31\%) women had pregnancy complication and from those 842(66.5\%) women booked for first ANC after three months while 424(33.5\%) respondents booked for first ANC checkup within the first three months. Among those pregnant women who had no pregnancy complication, 1277(71\%) women attended their first ANC after 3 months whereas the rest 522(29\%) women attended within three months. From 2766 (90.24\%) pregnant women who had never faced pregnancy termination, only eight hundred sixty (31.1\%) women booked their first ANC contact at recommended time (Table 1).

\section{Antenatal Care Service-Related Characteristics}

Even though the majority of respondents' pregnancy was planned 2796(91.2\%), but from women who planned to have pregnancy in this study only $872(31.2 \%)$ women were booked for their first antenatal care check early. Majority of respondents $(87.01 \%)$ had no media access to get information about 
antenatal care earlier. From those respondents only seven hundred eight one (29.3\%) women booked for first ANC within twelve weeks. Among 1466(47.83\%) pregnant mothers having big distance problem, 1004(68.5\%) were not booked for their first ANC visit (Table 1).

\section{Association Of Timing Of The First Antenatal Care Visit And Associated Risk Factors In Rural Parts Of Ethiopia Using Binary Logistic Regression Analysis}

Multivariable binary logistic regression used to identify the variables, which had significant effect on the first ANC visit in this study. The variables those were significant in the univariable analysis were included in the final multivariable analysis. As shown in the Table 2, the odds ratio for secondary and above educated women is AOR $=1.52$ with p-value 0.02 . This implies that women who attended secondary and above formal education were 1.52 times more likely to visit first ANC booking timely compared to women who were not attended education. Women in age group 30-34 year had odds ratio $\mathrm{AOR}=1.57$ with p-value 0.02 , which indicates that mothers in age group 30-34 is exceeds in age group 15-19 by 57\% to visit ANC earlier. The odds ratio for women in age group 35-39 is AOR $=1.56$ with p-value $=0.03$, which implies that women in age group 35-39 is 1.56 times more likely to experience early ANC visit than women in age group 15-19 (Table 2).

The odds ratio for women from Amhara region is $\mathrm{AOR}=0.71$ with p-value 0.02 , Gambela region $\mathrm{AOR}=0.60$ with p-value 0.01 , Harari region $\mathrm{AOR}=0.36$ with p-value 0.0001 and Dire Dawa city administration $\mathrm{AOR}=0.25$ with p-value 0.0001 . Which implies that women from Amahara, Gambela, Harari and Dire Dawa city administration were less likely to visit health facility for ANC earlier compared to women from Tigray region. The odds ratio for Benishangul Gumuz region AOR $=1.53$ with p-value0.01 and for SNNPR AOR $=1.63$ with p-value 0.0001 , which revealed that women from Benishangul Gumuz and SNNPR were more likely to experienced earlier visit than women from Tigray region (Table 2).

Women who had media access in their surroundings odds ratio is AOR $=2.4$ with p-value 0.04 , which implies that women who had media access were 2.4 times more likely to experienced ANC visit in the first three months of gestation compared to women without any media access in their surroundings. The odds ratio for women who had their own works AOR $=0.69$ with p-value 0.0001 and for house wives AOR $=0.75$ with p-value 0.01, which implies that women who had their own work and house wives were 0.69 and 0.75 times less likely to visit early antenatal care compared to women who has no work respectively. The distance from home to health facility was big problem odds ratio $\mathrm{AOR}=0.43$ with $\mathrm{p}$-value 0.03 , it revealed that women who had big distance problem were 0.43 times less likely to experienced antenatal care visit in the first three months compared to women who had no distance problem. The odds ratio for women whose wealth index richer is AOR $=1.29$ with p-value 0.0001 , this result revealed that women from richer wealth index is 1.29 times were more likely to visit earlier than women were from poorer.

The odds ratio for women having pregnancy complication is AOR $=1.29$ with p-value 0.0001 , which implies that women with pregnancy complication were 1.29 times more likely to attend antenatal care service within the first three months than women without pregnancy complication. Women who had planned to have pregnancy odds ratio is $\mathrm{AOR}=1.26$, it implies that women who planned to have pregnancy were 1.26 times more likely to attend the first ANC visit earlier compared to mothers who were not planned to have pregnancy (Table 2).

\section{Discussion}

In this study, both descriptive and inferential analyses introduced to identify the highly significant variables those influences the early booking of pregnant women in rural parts of country. According to the World Health Organization (WHO) recommendation, every pregnant mother should start ANC booking during the first trimester of pregnancy (Irene M, 2009). However, several studies done in Ethiopia revealed that a significant proportion of women from rural Ethiopia do not start ANC according to the WHO recommendation (Teshale A., 2020; Feleke G., 2015). 


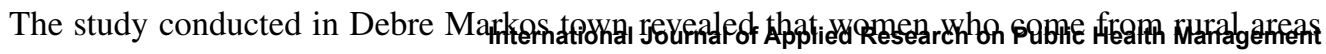

Volume 7 • Issue 1 • January-June 2022

Table 1. Descriptive summaries of timing of the first ANC visit and associated risk factors (EDHS 2016)

\begin{tabular}{|c|c|c|c|c|}
\hline & & \multicolumn{2}{|c|}{ Timing of first ANC in months } & \multirow{3}{*}{$\begin{array}{l}\text { Total } \\
\text { Frequency (\%) }\end{array}$} \\
\hline & & Early (£ 3 months) & Late ( $>3$ months) & \\
\hline Variables & Categories & Frequency $(\%)$ & Frequency $(\%)$ & \\
\hline Maternal age & $\begin{array}{l}15-19 \\
20-24 \\
25-29 \\
30-34 \\
35-39 \\
40-44 \\
45-49\end{array}$ & $\begin{array}{l}65(36.7) \\
238(34.8) \\
273(31.9) \\
176(27.2) \\
119(26.4) \\
53(29.3) \\
22(31.4)\end{array}$ & $\begin{array}{l}112(63.3) \\
446(65.2) \\
583(68.1) \\
470(7.8) \\
332(73.6) \\
128(70.7) \\
48(68.6)\end{array}$ & $\begin{array}{l}177(5.77) \\
684(22.32) \\
856(27.93) \\
646(21.08) \\
451(14.71) \\
181(5.91) \\
70(2.28)\end{array}$ \\
\hline Women occupation & $\begin{array}{l}\text { Not working } \\
\text { Employed } \\
\text { Private work } \\
\text { House wives } \\
\text { Others }\end{array}$ & $\begin{array}{l}495(29.3) \\
11(52.8) \\
172(35.9) \\
215(31.8) \\
53(26.4)\end{array}$ & $\begin{array}{l}1192(70.7) \\
10(47.2) \\
30(64.1) \\
462(38.2) \\
148(73.6)\end{array}$ & $\begin{array}{l}1687(55.04) \\
21(0.69) \\
479(15.63) \\
677(22.09) \\
201(6.56)\end{array}$ \\
\hline Women education level & $\begin{array}{l}\text { No education } \\
\text { Primary } \\
\text { Secondary \& above }\end{array}$ & $\begin{array}{l}540(28.7) \\
315(32.1) \\
91(44.4)\end{array}$ & $\begin{array}{l}1340(71.3) \\
664(67.9) \\
144(55.6)\end{array}$ & $\begin{array}{l}1880(61.34) \\
980(31.97) \\
205(6.69)\end{array}$ \\
\hline Marital Status & $\begin{array}{l}\text { Single } \\
\text { Married } \\
\text { Widowed } \\
\text { Divorced }\end{array}$ & $\begin{array}{l}444(28.9) \\
372(30.5) \\
81(38.8) \\
49(48)\end{array}$ & $\begin{array}{l}1092(71.1) \\
846(69.5) \\
128(61.2) \\
53(52)\end{array}$ & $\begin{array}{l}1536(50.11) \\
1218(39.74) \\
209(6.82) \\
102(3.33)\end{array}$ \\
\hline Region & $\begin{array}{l}\text { Tigray } \\
\text { Afar } \\
\text { Amhara } \\
\text { Oromia } \\
\text { Somalia } \\
\text { Benishangul } \\
\text { SNNP } \\
\text { Gambela } \\
\text { Harari } \\
\text { Dire Dawa }\end{array}$ & $\begin{array}{l}144(30.3) \\
58(27.9) \\
152(37.6) \\
117(26.7) \\
63(29.6) \\
76(22.6) \\
110(20.4) \\
71(40.8) \\
82(55.4) \\
73(57.4)\end{array}$ & $\begin{array}{l}332(69.7) \\
150(72.1) \\
252(62.4) \\
321(73.3) \\
150(70.4) \\
260(77.4) \\
430(79.6) \\
103(59.2) \\
66(44.6) \\
55(43.0)\end{array}$ & $\begin{array}{l}476(15.53) \\
208(6.79) \\
404(13.18) \\
438(14.29) \\
213(6.95) \\
336(10.96) \\
540(17.62) \\
174(15.68) \\
148(4.83) \\
128(4.18)\end{array}$ \\
\hline Media access & $\begin{array}{l}\text { No } \\
\text { Yes }\end{array}$ & $\begin{array}{l}781(29.3) \\
165(44.8)\end{array}$ & $\begin{array}{l}1886(70.7) \\
233(58.5)\end{array}$ & $\begin{array}{l}2667(87.01) \\
398(12.98)\end{array}$ \\
\hline Wealth index & $\begin{array}{l}\text { Poorer } \\
\text { Middle } \\
\text { Richer }\end{array}$ & $\begin{array}{l}457(28.5) \\
208(32.9) \\
281(34)\end{array}$ & $\begin{array}{l}1149(71.5) \\
424(67.1) \\
546(66)\end{array}$ & $\begin{array}{l}1606(52.40) \\
632(20.62) \\
827(26.98)\end{array}$ \\
\hline Pregnancy termination & $\begin{array}{l}\text { Yes } \\
\text { No }\end{array}$ & $\begin{array}{l}86(28.8) \\
860(31.1)\end{array}$ & $\begin{array}{l}213(71.2) \\
1906(68.9)\end{array}$ & $\begin{array}{l}299(9.76) \\
2766(90.24)\end{array}$ \\
\hline pregnancy complication & $\begin{array}{l}\text { Yes } \\
\text { No }\end{array}$ & $\begin{array}{l}424(33.5) \\
522(29.0)\end{array}$ & $\begin{array}{l}842(66.5) \\
1277(71.0)\end{array}$ & $\begin{array}{l}1266(41.31) \\
1799(58.69)\end{array}$ \\
\hline Husband occupation & $\begin{array}{l}\text { Not working } \\
\text { Employed } \\
\text { Private work } \\
\text { Farmers } \\
\text { Others }\end{array}$ & $\begin{array}{l}77(31.4) \\
47(41.6) \\
199(29.8) \\
513(30.9) \\
110(29.0)\end{array}$ & $\begin{array}{l}168(68.6) \\
66(58.4) \\
468(71.2) \\
1147(69.1) \\
270(71)\end{array}$ & $\begin{array}{l}245(7.99) \\
113(3.69) \\
667(21.76) \\
1660(54.16) \\
380(12.40)\end{array}$ \\
\hline Husbands education level & $\begin{array}{l}\text { No education } \\
\text { Primary } \\
\text { Secondary \& above }\end{array}$ & $\begin{array}{l}416(29.6) \\
356(29.2) \\
174(39.4)\end{array}$ & $\begin{array}{l}989(70.4) \\
862(70.8) \\
268(60.6)\end{array}$ & $\begin{array}{l}1405(45.84) \\
1218(39.74) \\
442(14.42)\end{array}$ \\
\hline $\begin{array}{l}\text { Distance from health } \\
\text { facility }\end{array}$ & $\begin{array}{l}\text { No problem } \\
\text { Big problem } \\
\text { Not a big problem }\end{array}$ & $\begin{array}{l}112(29.7) \\
462(31.5) \\
372(30.4)\end{array}$ & $\begin{array}{l}265(70.3) \\
1004(68.5) \\
850(69.6)\end{array}$ & $\begin{array}{l}377(12.30) \\
1466(47.83) \\
1222(39.87)\end{array}$ \\
\hline Peer influence & $\begin{array}{l}\text { No problem } \\
\text { Big problem } \\
\text { Not a big problem }\end{array}$ & $\begin{array}{l}33(35.1) \\
276(31.1) \\
637(30.6)\end{array}$ & $\begin{array}{l}61(64.9) \\
612(68.9) \\
1446(69.4)\end{array}$ & $\begin{array}{l}94(3.07) \\
888(28.97) \\
3065(67.96)\end{array}$ \\
\hline Plan of pregnancy & $\begin{array}{l}\text { Planned } \\
\text { Not planned }\end{array}$ & $\begin{array}{l}872(31.2) \\
74(27.5)\end{array}$ & $\begin{array}{l}1924(68.2) \\
195(72.5)\end{array}$ & $\begin{array}{l}2796(91.2) \\
269(8.78)\end{array}$ \\
\hline
\end{tabular}


Table 2. Binary logistic regression Analysis result of timing of first ANC visit in rural Ethiopia (EDHS 2016)

\begin{tabular}{|c|c|c|c|c|}
\hline Variables & Categories & Estimates & AOR (95\% CI) & p-value \\
\hline \multirow[t]{3}{*}{ Women education level } & No education & & 1 & \\
\hline & Primary & 0.07 & $1.07(0.89,1.13)$ & 0.48 \\
\hline & Secondary and above & 0.42 & $1.52(1.09,2.34)$ & $0.02 *$ \\
\hline \multirow[t]{7}{*}{ Maternal age } & $15-19$ & & 1 & \\
\hline & $20-24$ & 0.12 & $1.13(0.79,1.61)$ & 0.50 \\
\hline & $25-29$ & 0.20 & $1.22(0.85,1.73)$ & 0.28 \\
\hline & $30-34$ & 0.45 & $1.57(1.07,2.27)$ & $0.02 *$ \\
\hline & $35-39$ & 0.44 & $1.56(1.04,2.31)$ & $0.03 *$ \\
\hline & $40-44$ & 0.36 & $1.44(0.89,2.32)$ & 0.13 \\
\hline & $45-49$ & 0.22 & $1.244(0.67,2.36)$ & 0.50 \\
\hline \multirow[t]{10}{*}{ Region } & Tigray & & 1 & \\
\hline & Afar & -0.14 & $0.88(0.59,1.29)$ & 0.49 \\
\hline & Amhara & -0.34 & $0.71(0.53,0.95)$ & $0.02 *$ \\
\hline & Oromia & 0.15 & $1.16(0.86,1.57)$ & 0.34 \\
\hline & Somali & -0.19 & $0.82(0.57,1.20)$ & 0.31 \\
\hline & Benishangul Gumuz & 0.43 & $1.53(1.11,2.14)$ & $0.01 *$ \\
\hline & SNNPR & 0.49 & $1.63(1.21,2.21)$ & $0.00 *$ \\
\hline & Gambela & -0.51 & $0.60(0.41,0.87)$ & $0.01 *$ \\
\hline & Harari & -1.01 & $0.36(0.24,0.54)$ & $0.00 *$ \\
\hline & Dire Dawa & -1.38 & $0.25(0.16,0.38)$ & $0.00^{*}$ \\
\hline \multirow[t]{2}{*}{ Media access } & No & & 1 & \\
\hline & Yes & 0.88 & $2.4(1.34,2.85)$ & $0.04 *$ \\
\hline \multirow[t]{5}{*}{ Women occupation } & No work & & 1 & \\
\hline & Employed & -0.25 & $0.78(0.30,2.01)$ & 0.61 \\
\hline & private workers & -0.37 & $0.69(0.55,0.87)$ & $0.00 *$ \\
\hline & House wives & -0.29 & $0.75(0.60,0.93)$ & $0.01 *$ \\
\hline & Others & -0.03 & $0.97(0.69,1.38)$ & 0.85 \\
\hline \multirow{3}{*}{$\begin{array}{l}\text { Distance from health } \\
\text { facility }\end{array}$} & No problem & & 1 & \\
\hline & Big problem & -0.32 & $0.43(0.35,0.83)$ & $0.03^{*}$ \\
\hline & Not big problem & -0.12 & $0.89(0.53,2.31)$ & 0.13 \\
\hline \multirow[t]{3}{*}{ Wealth index } & Poorer & & 1 & \\
\hline & Middle & 0.13 & $1.13(0.91,1.53)$ & 0.12 \\
\hline & Richer & 0.26 & $1.29(1.03,1.51)$ & $0.00 *$ \\
\hline \multirow[t]{2}{*}{ Pregnancy complication } & No & & 1 & \\
\hline & Yes & 0.26 & $1.29(1.03,1.51)$ & $0.00^{*}$ \\
\hline \multirow[t]{2}{*}{ Plan for pregnancy } & No & & 1 & \\
\hline & Yes & 0.23 & $1.26(0.61,2.12)$ & $0.02 *$ \\
\hline
\end{tabular}

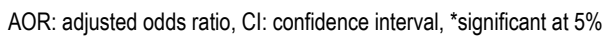


were 2.8 times more likely late than urban women and from total participants, $56 \%$ of rural and $27 \%$ of urban residents were booked first ANC after 16 weeks of gestation. It also showed that more than half of women visited antenatal care service in the first trimester, which implies that women who were residing in the urban were experienced ANC service early than rural residing women (Ewunetie et al., 2018). This might be due to socio-demographic, Fertility related and ANC related characteristics as evidence by the fact that majority of pregnant women had no education and only attained primary school; more than half of women living in rural areas were house wives as compared to urban residents of Ethiopian.

Thus, this study attempted to assess factors that determine timing of the first antenatal care visit and associated risk factors in rural parts of Ethiopia. In our study, about $31 \%$ of the pregnant women initiated antenatal care at or before three months of gestation, which agree with the study done in Ethiopia about the changes over-15 year span 32\% (Ousman SK, 2019) and Vietnam rural mothers (Toan TK., 2012). However, this study result is inconsistent with the study done in Nepal, which revealed that $70 \%$ of pregnant mothers received first ANC within the first four months (Yuba R., Trishna J., Suresh M., 2017). From mothers who were not attended education, only $28.7 \%$ contacted to the health professional and booked for first ANC visit earlier. In our study, 31.8\% of housewife mothers followed their first ANC within the first trimester, this study result is in line with the study conducted in Gonder town which revealed that from pregnant mothers who were unable to read and write, only $28 \%$ received first ANC within the first three months. This study also revealed that $31.7 \%$ of house wife women booked for their first ANC timely (Gudayu et al., 2014). Only 27.5\% of respondents who had no plan for the pregnancy were booked for their first antenatal care check early. The study done in South Gondar which showed that from those mothers who had no plan for the pregnancy, only $17.3 \%$ used the opportunity to early receive their first ANC contact within the first trimester (Wolde et al., 2019).

Women who had private business work and house wives had decreased odds of booking ANC early than those women who had no work. The evidence may be the workload of housewives in the house and the lack of time to visit health facilities. In addition, the private business worker were not initiated for ANC service early, due to lack of time, and busy to fulfill basic needs for their families, this result is consistent with study done in Addis Zemen primary hospital South Gondar (Wolde et al., 2019) and in Tanzania (Njiku F., 2017). Pregnant women from richer household were 1.29 times more likely to attend early for their first ANC booking as compared to their counterparts with women from poorer household and this result is in line with the study done in Gamo Gofa Zone, South Ethiopia (Feleke G., 2015). Women in rural areas with age group 30-39 were more likely to have antenatal care services visit early compared women in age group 15-19, this result agreed with the study found in North West Ethiopia (Mulat G., 2015).

Women who had media access were more likely to experienced early booking of the first ANC service, this outcome is in line with the study conducted in Ethiopia on changes over-15-year span using 2005, 2011 and 2016 Ethiopian Demographic Health Survey (Ousman SK, 2019). Women having plan for pregnancy were more likely initiated for first antenatal care booking timely compared to those women who didn't have no plan for the pregnancy, this outcome is in line with preceding study conducted in Bahir Dar, Tigray and South Africa (Yibeltal A., 2018) (Lerebo W., 2015; Ebonwu J. et al., 2018). This might be due to when the mother wanted the pregnancy, she is ready to keep the health of the baby and as the result they are happy to attain the contact timely.

Mothers having distance problem were less likely to be booked early compared with those mothers who had no distance problem, this finding is in line with the prior studies conducted in Ethiopia (Teshale A., 2020) and Cameron (Tolefac PN et al., 2017). Women having secondary and above educational level were more likely to attend ANC service within the first three months, this study is consistent with a study done in North West Ethiopia (Ewunetie et al., 2018), Gondar (Belayneh T., 2014), Kembata Tambaro zone (Tekelab T., 2014), Tanzania (Gross K., 2012) and Ghana (Tayie FA., 2008). There might be high chance for educated mothers to have an information access about antenatal 
care service than those uneducated mothers. Mothers who had pregnancy complication more likely to attend their first ANC early compared to those who did not have any pregnancy complication. This result agreed with several studies done in Axum town (Gebresilassie et al., 2019), Mekelle (Fisseha G., 2015) and Benin (Ouendo E-M, 2015). This might be because of antenatal care is perceived by the mothers as medicinal rather than the preventive measure that is why the mothers start ANC timely if they get any pregnancy related illness.

\section{Conclusion}

There is high prevalence of late antenatal care visit in Ethiopia especially in the rural area still now. In our study, we have identified the factors those determine the early timing of antenatal care service of the pregnant women in rural parts of Ethiopia. Mothers who were uneducated, having private business work, having distance problem, lack of media, having poorer economic status and having unplanned pregnancy were significantly associated with decreased odds of early timing of first antenatal care visits. According to the findings the listed categories of variables were highly influenced the timing of antenatal care visit within first three months of gestation.

\section{Recommendations}

Pregnant mother have to attend ANC service even though she had no pregnancy complication. The next recommendation will be education, which is a key strategic area addressed by the ministry of education of Ethiopian in improving women's awareness towards ANC during a pregnancy. Poverty reduction is another area of intervention that needs addressed by the concerned body of Ethiopian government. Expansion of infrastructure among the rural community needs prioritization by the concerned body of Ethiopian government, to improve ANC service utilization. Government of Ethiopia has to expand the media coverage related to ANC throughout the country and mothers have to be aware of the importance of ANC during pregnancy. Awareness should be given for all women in the reproductive age group about timely booking within the first three months. The Central Statistical Agency, recommended including variables that discussed in literature review that may affect utilization of ANC visits.

\section{Limitation of the Study}

The study used data from national surveys that have inherent gaps such as absence of some variables that may affect the response variable and some variables are not included because of large number of missing values like parity. Another potential limitation of this study was the cross-sectional nature of the analysis. The study uses reported characteristics of mothers that may vary within time.

\section{Abbreviations}

ANC: Antenatal Care

EDHS: Ethiopian Demographic and Health Survey

WHO: World Health Organization

\section{Declarations}

\section{Ethics Approval And Consent To Participate}

Ethical clearance for this study was obtained from Ethiopian Health and Nutrition Research Institute (EHNRI) Review Board, the National Research Ethics Review Committee (NRERC) at the Ministry of Science and Technology, the Institutional Review Board of ICF International, and the communicable disease control (CDC). The author requested access to the data from demographic health survey program team and access was granted to use the data for this study. 


\section{Consent for Publication}

Not applicable.

\section{Availability of Data and Materials}

The datasets used in this study available from the corresponding author on reasonable request.

\section{Competing Interest}

The authors declare that there is no competing interest.

\section{Funding}

No funding available

\section{Authors' Contributions}

All authors designed the study, participated in the data extraction, performed analysis, interpreted results, drafted, and revised the manuscript. Finally, all authors read and approved the manuscript.

\section{ACKNOWLEDGMENT}

We would like to thanks Ethiopian demographic health survey teams for this nice data collected from all parts of country and for sending authorization letter to us, to generate and continue this study using data set from their database. 


\section{REFERENCES}

Abate,, M. G. (2020). Proximate determinants of infant mortality in Ethiopia, 2016 Ethiopian demographic and health surveys: Results from a survival analysis. Archives of Public Health, 78, 4. doi:10.1186/s13690-019-0387-4

Abraha, A. M. A. (2019). Social determinants of under-5 child health: A qualitative study in Wolkayit Woreda, Tigray Region, Ethiopia. PLoS One, 14(6), e0218101. doi:10.1371/journal.pone.0218101

Acharya, D. K. V. (2015). Impact of mass media on the utilization of antenatal care services among women of rural community in Nepal. BMC Research Notes, 8, 345. doi:10.1186/s13104-015-1312-8

Aheto, K. J. M. (2019). Predictive model and determinants of under-five child mortality: Evidence from the 2014 Ghana demographic and health survey. BMC Public Health, 19, 64. doi:10.1186/s12889-019-6390-4

Alam, M. M. R. (2014). Statistical modeling of the number of deaths of children in Bangladesh. Biometrics \& Biostatistics International Journal, 1(3).

Alkema, L. C. D. (2016). Global, regional, and national levels and trends in maternal mortality between 1990 and 2015, with scenario-based projections to 2030: A systematic analysis by the UN Maternal Mortality Estimation Inter-Agency Group. Lancet, 387(10017), 462-474. doi:10.1016/S0140-6736(15)00838-7

Amare, D. F. T. (2007). Determinants of under-five mortality in Gilgel Gibe Field Research Center, Southwest Ethiopia. The Ethiopian Journal of Health Development, 21(2).

Assefa, E. T. M. (2017). Factors related to the use of antenatal care services in Ethiopia: Application of the zero-inflated negative binomial model. Women \& Health, 7, 804-821. doi:10.1080/03630242.2016.1222325

Ayele,, D. G. (2016). Comparison of under-five mortality for 2000, 2005 and 2011 surveys in Ethiopia. BMC Public Health, 16, 930.

Bekele, Y. G. (2016). Survival analysis of under-five mortality of children and its associated risk factors in ethiopia. Journal of Biosensors \& Bioelectronics, 7, 213.

Belayneh, T. A. M. (2014). Previous early antenatal service utilization improves timely booking: Cross-sectional

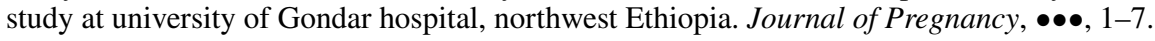

Berhanu, T. (2019). Socioeconomic, Demographic, and Environmental Determinants of Under-5 Mortality in Ethiopia: Evidence from Ethiopian Demographic and Health Survey, 2016. Child Development Research.

Collins, Z. B. M. (2015). The effect of mass media campaign on Men's participation in maternal health: A crosssectional study in Malawi. Reproductive Health, 12, 31. doi:10.1186/s12978-015-0020-0

Cox, D. (1972). Regression models and life tables (with discussions). Journal of the Royal Statistical Society. Series A (General), 34, 187-220.

CSA. (2016). Central Statistical Agency (CSA) [Ethiopia] and ICF, Ethiopia Demographic and Health Survey 2016. CSA and ICF.

Dereje,, T. Z. (2018). Determinants of Under-Five Mortality in Ethiopia: An Application of Cox Proportional Hazard and Frailty Models. Turkiye Klinikleri J Biostat, 10(2), 123-136.

Ebonwu, J. (2018a). Determinants of late antenatal care presentation in rural and peri-urban communities in South Africa: A cross-sectional study. PLoS One.

Ewunetie, . (2018). DELAY on first antenatal care visit and its associated factors among pregnant women in public health facilities of Debre Markos town, North West Ethiopia. BMC Pregnancy and Childbirth, $18,173$.

Ewunetie, . (2018b). DELAY on first antenatal care visit and its associated factors among pregnant women in public health facilities of Debre Markos town, North West Ethiopia. BMC Pregnancy and Childbirth, 18(173).

Ezeh, O. K. K. E. (2015). Risk factors for postneonatal, infant, child and under-5 mortality in Nigeria: a pooled cross-sectional analysis. BMJ Open, 5(3). 
Feleke, G. Y. D. (2015). Timing of First Antenatal Care Attendance and Associated Factors among Pregnant Women in Arba Minch Town and Arba Minch District, Gamo Gofa Zone, South Ethiopia. Hindawi Publishing Corporation: Journal of Environmental and Public Health, 2015, 7.

Fisseha, G. M. G. (2015). Predictors of timing of first antenatal care booking at public health centers in Mekelle City, Northern Ethiopia. J Gynecology Obstetrics., 3(3), 55-60.

FMOH. (2010). Health Sector Development Programme IV (HSDP) 2010/11--2014/15. FMOH.

FMOH. (2014). Accelerated Plan for Scaling up PMTCT Services in Ethiopia. Federal Ministry Of Health.

Gebresilassie, . (2019). Timing of first antenatal care attendance and associated factors among pregnant women in public health institutions of Axum town, Tigray, Ethiopia, 2017: A mixed design study. BMC Pregnancy and Childbirth, 19(340).

Gross K., A. S. (2012). Timing of antenatal care for adolescent and adult pregnant women in South-Eastern Tanzania. BMC Pregnancy Childbirth., 12(1).

Gudayu, . (2014). Timing and factors associated with first antenatal care booking among pregnant mothers in Gondar Town; North West Ethiopia. BMC Pregnancy and Childbirth.

Gyimah, S. O. (2003). A cohort analysis of the timing of first birth and fertility in Ghana. Population Research and Policy Review, 22(3), 251-266.

Irene, M. J. H. (2009). Chang and Adaptation in Pregnancy. In M. Diane \& A. Margaret (Eds.), Mayles Text Book For Midwives. Churchill Livingstone: Elsevier.

Kayode, G. A. V. T. (2012). Risk factors and a predictive model for under-fve mortality in Nigeria:Evidence from Nigeria demographic and health survey. BMC Pregnancy and Childbirth, 12.

Kazembe, L. A. C. (2012). Childhood mortality in sub-Saharan Africa: cross-sectional insight into small-scale geographical inequalities from Census data. BMJ Open, 2.

Lerebo, W. K. (2015). Magnitude and Associated Factors of Late Booking for Antenatal Care in Public Health Centers of Adigrat Town, Tigray, Ethiopia. Clinics in Mother and Child Health, 171, 12.

Michael, N.K. (2018). Risk Factors for Child Mortality in the Kassena-Nankana District of Northern Ghana: A Cross-Sectional Study Using Population-Based Data. Hindawi Scientifica. https://doi.org/.10.1155/2018/7692379

Mugo, N. S. K. E. (2018). Determinants of neonatal, infant and underfve mortality in a war-afected country: analysis of the 2010 Household Health Survey in South Sudan. BMJ Global Health, 3(1).

Mulat, G. T. (2015). Antenatal Care Service Utilization and its Associated Factors among Mothers who Gave Live Birth in the Past One Year in Womberma Woreda, North West Ethiopia. Epidemiology (sunnyvale). Epidemiology: Open Access.

Muluken, G. (2015). Social Determinants of Under-Five Mortality in Ethiopia: Issue Brief for Stakeholders. International Journal of Public Health Research, 3(2), 64-66.

Njiku, F. W. H. (2017). Prevalence and factors associated with late antenatal care visit among pregnant women in Lushoto, Tanzania. Tanzania Journal of Health Research, 19(3).

Ouendo,, E-M. (2015). Determinants of low antenatal care services utilization during the first trimester of pregnancy in southern Benin rural setting. Universal Journal of Public Health, 3(5), 220-227.

Ousman,, S.K. (2019). Social Determinants of Antenatal Care Service Use in Ethiopia: Changes Over a 15-Year Span. Frontiers in Public Health, 7, 161. doi:10.3389/fpubh.2019.00161

Solomon, G. (2016). Determinants of Under-Five Mortality in High Mortality Regions of Ethiopia: An Analysis of the 2011 Ethiopia Demographic and Health Survey Data. International Journal of Population Research. Advance online publication. doi:10.1155/2016/1602761

Tayie,, F.A. (2008). Antenatal care and pregnancy outcome in Ghana, the importance of women's education. African Journal of Food, Agriculture, Nutrition and Development, 8(3), 291-303. 
Tekelab, T. B. (2014). Factors associated with late initiation of antenatal care Factors associated with late initiation of antenatal care Centers in Kembata Tembaro zone, southern Ethiopia. Science, Technology and Arts Research Journal, 3(1), 108-115.

Teshale, A. T. G. (2020, July 6). Prevalence and associated factors of delayed first antenatal care booking among reproductive age women in Ethiopia; a multilevel analysis of EDHS 2016 data. PLoS One, 15(7).

Toan, T. K. (2012). Antenatal and delivery care utilization in urban and rural contexts in Vietnam. A study in two health and demographic surveillance sites. Academic Press.

Tolefac, P. N. (2017). Why do pregnant women present late for their first antenatal care consultation in Cameroon? Maternal health, neonatology and perinatology. Maternal Health, Neonatology and Perinatology, 3(1), 29.

Tuncalp,, Ö. L. T.-R. (2017). WHO recommendations on antenatal care for a positive pregnancy experienceGoing beyond survival. BJOG, 124, 860-862.

UNICEF. (2017). Estimates Developed by the UN Inter-agency Group for Child Mortality Estimation. UNICEF.

UNICEF. (2019). UNICEF - Definitions. www.unicef.org

Van Malderen. (2019). Socioeconomic factors contributing to under-five mortality in sub-Saharan Africa:a decomposition analysis. BMC Public Health, 19, 760. doi:10.1186/s12889-019-7111-8

WHO. (2019). Child mortality and causes of death. WHO.

WHO. (2020). WHO recommendations on antenatal care for a positive pregnancy experience, New guidelines. World Health Organization.

WHO. (2016). Maternal mortality: fact sheet. World Health Organization. http://www.who.int/mediacentre/ factsheets/fs348/en/index.html

Wolde, . (2019). Late initiation of antenatal care and associated factors among pregnant women in Addis Zemen primary hospital, South Gondar, Ethiopia. Reproductive Health, 16(73).

World Health Statistics. (2020). Monitoring health for the SDG, sustainable development goals. Geneva: World Health Organization, Licence: CC BY-NC-SA 3.0 IGO.

Yaya, S. G. B. (2018). Under fve mortality patterns and associated maternal risk factors in sub-Saharan Africa: A multi-country analysis. PLoS One, 13(10). Advance online publication. doi:10.1371/journal.pone.0205977

Yibeltal, A. A. A. (2018). Early initiations of first antenatal care visit and associated factor among mothers who gave birth in the last six months preceding birth in Bahir Dar Zuria Woreda North West Ethiopia. Reproductive Health, 203, 15.

Yuba, R., Trishna, J., \& Suresh, M. (2017, September 11). Timing of first antenatal care (ANC) and inequalities in early initiation of ANC in Nepal. Academic Press. 